\title{
Affecting commute mode choice in Southern California: Which employer-based strategies work?
}

\author{
Kevin Kane \\ Southern California Assn. of Governments \& \\ University of Southern California \\ kane@scag.ca.gov \\ Joseph Cryer \\ Southern California Assn. of Governments \\ cryer@scag.ca.gov
}

\author{
Jenneille Hsu \\ Southern California Assn. of Governments \\ jenneillehsu@gmail.com \\ Marco Anderson \\ Southern California Assn. of Governments \\ anderson@scag.ca.gov
}

\begin{abstract}
Interest in mandatory employer-based trip reduction (EBTR) programs has been renewed due to increased emphasis on reducing transportation-related greenhouse gas emissions. This paper analyzes survey data from 2004 to 2016 from an EBTR program in Southern California, known as Rule 2202, which allows employers with more than 250 workers to choose among implementing commute reduction strategies to meet performance standards, show evidence of obtaining omissions credits, or pay a fee-in-lieu. We report program statistics and conduct bivariate and regression analyses to determine which land-use and location characteristics, employer characteristics, and mitigation strategies explain cross-sectional differences in average vehicle ridership (AVR) and AVR improvement to understand where future AVR increases might be realized. Decreasing program participation suggests that alternatives to commute-reduction strategies make financial sense to regulated employers, but Rule 2202 employers report higher alternative transportation shares than the region as a whole. AVR is found to be highest at smaller worksites, in transit-supported and pedestrian-friendly neighborhoods, and where employers support vanpool programs. Multivariate analyses indicate that AVR gains were also highest in commercially dense neighborhoods, for retail businesses, and where guaranteed ride home programs were offered, showing promise for future AVR gains.
\end{abstract}

\section{Introduction}

Travel demand management (TDM) is defined a set of strategies intended to maximize traveler choices and reduce vehicle miles traveled (VMT) in order to reduce congestion, air pollu-

Copyright 2020 Kevin Kane, Jenneille Hsu, Joseph Cryer \& Marco Anderson http://dx.doi.org/10.5198/jtlu.2020.1558

ISSN: $1938-7849$ | Licensed under the Creative Commons Attribution - Noncommercial License 4.0

The Journal of Transport and Land Use is the official journal of the World Society for Transport and Land Use (WSTLUR) and is published and sponsored by the University of Minnesota Center for Transportation Studies.

Article history:

Received: April 1, 2019

Received in revised form:

December 31, 2019

Accepted: January 6, 2020

Available online: October 8, 2020 
tion, greenhouse gas emissions, and promote community integration (USDOT 2019; Salon, Boarnet, Handy, Spears, \& Tal, 2012). The TDM strategy highlighted in this paper is employer-based trip reduction (EBTR), a longstanding program in some regions requiring employers to measure employee commutes, incentivize alternative commute modes, and mandating a fee payment which can be reduced if a target such as average vehicle ridership (AVR) is met. Extant analyses of EBTR policies have generally found at least some evidence of program effectiveness in fostering alternatives to single-occupant vehicle (SOV) commutes (Dill \& Wardell, 2018; Kneisel, 2001; Zuehlke \& Guensler, 2007). Southern California's South Coast Air Quality Management District (SCAQMD) has had an EBTR program since the 1980s. Its current program is known as Rule 2202_On-Road Motor Vehicle Mitigation Options and requires all employers with more than 250 employees at a worksite to implement a program, submit emissions credits, or pay a fee-in-lieu if a certain AVR threshold is not met (Dill, 1998). Based on the Southern California Association of Governments' (SCAG) estimate, as of 2016 Rule 2202 applies to roughly 1340 employers and 1.2 million workers in the region (roughly 15\%).

The scope, goals, and popularity of EBTR programs have fluctuated since their inception. Fearing undue burdens to employers, the state of California decreased the scope of SCAQMD's mandatory EBTR program when it raised the employee size threshold from 100 to 250. The purpose of EBTR has also been questioned when, for example, a survey of Atlanta employers showed limited support for the principles of EBTR (Dill, 1998; Zuehlke \& Guensler, 2007). More recently, the benefits of EBTR have grown beyond their original goals of congestion management and air pollution reduction. As the connection between land use and transportation choice becomes more attenuated, AVR increase is also a goal of newer greenhouse gas (GHG) reduction targets such as those contained in California's SB375 or "Smart Growth" legislation which mandates that metropolitan planning organizations (MPOs) craft land use, housing, and transportation strategies to meet future GHG emission reduction targets (Skelton, 2008). Additionally, recent California state legislation mandates that employers of 50 or more in Los Angeles County provide similar commute benefits to their workers. While this does not include the same compliance and fee payments as Rule 2202, it is indicative of gradually shifting political attitudes surrounding TDM following the advent of smart growth legislation and GHG targets.

The objectives of this paper are to (1) understand the participation rates, characteristics, and spatial distribution of the large employers subject to Southern Californias EBTR program, (2) to use land-use and location characteristics, employer characteristics, and mitigation strategies to explain differences in AVR, and (3) to see which of these factors are most related to change in AVR over 2004-2016 in order to understand where future AVR increases (and associated VMT and GHG emissions reductions) might be realized.

This paper proceeds by reviewing relevant literature on EBTR and TDM and providing additional background on the SCAQMD's program. We provide summary statistics and trends from the SCAQMD survey results which cover program participants from 2004-2016. Geographic Information System (GIS) is used to associate employer sites with surrounding land-use and transportation characteristics derived from MPO and Census data. Finally, we use regression analysis to analyze which locational characteristics and mitigation strategies are associated with AVR as well as year-over-year AVR changes. We then summarize findings and provide recommendations for future policy. 


\section{$2 \quad$ Literature and background}

\section{$2.1 \quad$ EBTR research}

Senate Bill (SB) 375 represented a dramatic shift in regional planning in California and placed a broad mandate on MPOs to investigate and advance land-use and transportation strategies which reduce GHG emissions. For example, SCAG's most recently adopted Regional Transportation Plan/Sustainable Communities Strategy (RTP/SCS) models the impact of several strategies on future travel demand including TDM, regional bikeway networks, car sharing programs, sidewalk upgrades, zero-emission vehicle availability, and efforts to promote active transportation (SCAG, 2016). Furthermore, land-use strategies such as promoting growth in job centers and pedestrian-friendly areas may be longer-range in nature but complement transportation improvements in an effort to satisfy SB375's mandate for a 19\% GHG emission reduction below 2005 levels by 2035 in Southern California. While neither SB375 nor SCAG's plan directly involves EBTR, it could be an important complementary tool for GHG reduction.

EBTR programs are generally strategies for criteria air pollutant management and predate collective action addressing GHG emissions. While considerable legislative and planning effort has been placed into SB375 in the last decade, EBTR's fate has been varied. In 1995, during a period of intense probusiness legislation, California prohibited EBTR programs from applying to employers of below 250 employees, citing implementation costs (largely the cost to employers of surveying their workers' travel behavior), limited effectiveness, inconsistent enforcement, and the perception that it represented a violation of the employee-employer relationship (Dill, 1998). Zuehlke and Guensler (2007) report similar findings in their survey of employer perceptions toward Atlanta's EBTR program—generally negative reactions that employers see minimal benefit to the programs, employees lack interest, and upper management does not provide support.

Empirical research has taken up the question of whether EBTR programs are effective at changing workers' commuting patterns. In a 2004 survey of employers in the Denver, Houston, San Francisco, and Washington DC, Herzog et al. reported that financial incentives including transit pass subsidies, carpool coordination, bicycle facilities, and liberal telework policies were associated with a $15 \%$ reduction in trips and VMT (Herzog, Bricka, Audette, \& Rockwell, 2006). Nonfinancial strategies, which consisted of marketing programs and informational campaigns as well as perceptions of a company's focus on alternative commute options, still showed a 7\% reduction in trips and VMT compared to a control group. This suggested that while actual compensation induced greater behavioral change, nonfinancial strategies were still effective.

Analyses of EBTR in California have suggested that modest trip reduction resulted from Rule 2202. Kneisel uses the employee size threshold change in 1997 as a natural experiment, finding a modest decline in AVR at employers who were no longer subject to the rule (Kneisel, 2001). Despite the dip in overall performance, AVR showed no change at employers who had previously elected to implement a commute reduction strategy under Rule 2202. This suggests that performance is more closely linked to employer motivation than the rule itself; however, it may have been the rule which "nudged" certain employers to actively promote alternatives. Dill and Wardell conduct an evaluation of the Portland, Oregon area's 50-employee-and-above EBTR law (Dill \& Wardell, 2018). The authors conduct crosssectional models of commute mode share, finding that a variety of locational and programmatic considerations were related to transit, walking, or biking share. Having a downtown location, high nearby retail density, good street connectivity, and proximity to light rail or frequent bus service were significant predictors of lower SOV shares. In addition, offering discounted transit passes, a guaranteed ride home program, flextime, or compressed work week options increased transit ridership region-wide. However, 
the authors note the difficulty in inferring causality in their cross-sectional model. Furthermore, the fact that the strongest predictor of non-SOV share was whether or not an employer was located in Portland's downtown suggests that improving this measure can only be addressed by promoting business relocation toward downtown.

No studies of which we are aware investigate changes in AVR to measure elements of EBTR program effectiveness or for the purpose of identifying supportive employer or land-use and location characteristics. While land use is only minimally treated in extant EBTR programs, its impact on travel demand is complex and involves both local and regional factors (Ewing \& Cervero, 2010). While local activity clustering can reduce trip length and promote mode substitution, regional connectivity can aggregate labor demand in specific intraurban areas—downtowns or job centers—and increase transportation options even for longer trips. Since most travel data are home-based rather than work-based, the contribution of worksite land-use characteristics on travel is less frequently analyzed but may still be important. Additionally, advances in GIS analysis have increased the feasibility of using improved measures of neighborhood space- - e.g., parcels or blocks plus those within a certain distance - to better characterize the environment surrounding a point in urban space (Clark, Anderson, Östh, \& Malmberg, 2015; Hipp \& Boessen, 2013).

\subsection{Southern California's EBTR program today}

The SCAQMD offers three compliance options for the region's large employers. The first option is the Employee Commute Reduction Program (ECRP), which involves deploying an annual survey to all workers asking how they traveled to work each day during the past week. This is used to calculate an employer-level measure of AVR which takes into account telecommuting, compressed work weeks, the size of a carpool, and any other commute type. Following the SCAQMD's guidelines AVR is calculated as the number of employees arriving at the worksite between 6-10am divided by the number of vehicles arriving during the same time. An employer's AVR is compared to a target threshold based on the worksite's intraurban location (see Figure 1), a delineation of three zones which recognizes an employer's land use and transportation context, though fairly minimally. Employers in Zone 1-which is downtown Los Angeles-have an AVR target of 1.75 consistent with the areas high density and variety of nonvehicular commute options. The vast majority of the region is in Zone 2 and has a target of 1.5, while the outlying desert portions - many of which are not urbanized areas - have a target of 1.3.

An employer who misses the target can comply by undertaking approved commute mitigation strategies. The menu includes 26 strategies - 15 of which must be selected to receive full credit. Of the 15 , five strategies each must be chosen from the basic, marketing, and direct strategy lists. These include a variety of parking incentives, rideshare and vanpooling systems, bicycling support, flex/compressed schedules, guaranteed ride home programs, transit subsidies, and several others. A small number of employers who conduct the AVR survey but do not wish to implement mitigation strategies can pay a fee for the difference between their target and actual AVR, referred to as an "offset" strategy.

The second option is the Air Quality Investment Program (AQIP) which, as of July 2018, charges the employer a fee of $\$ 46.73$ for each employee who arrives during the peak window. Fee revenues are used to fund mobile emission projects. No survey is required, thus detailed data are unavailable. The final option allows an employer to satisfy Rule 2202 requirements by purchasing emission credits in California's carbon market and is referred to as Emission Reduction Strategies (ERS). This option also does not require employee surveys or the submittal of commute reduction strategies for review and reinvests the funds to promote energy efficiency elsewhere. 
Rule 2202-eligible worksites by compliance option and performance target zone

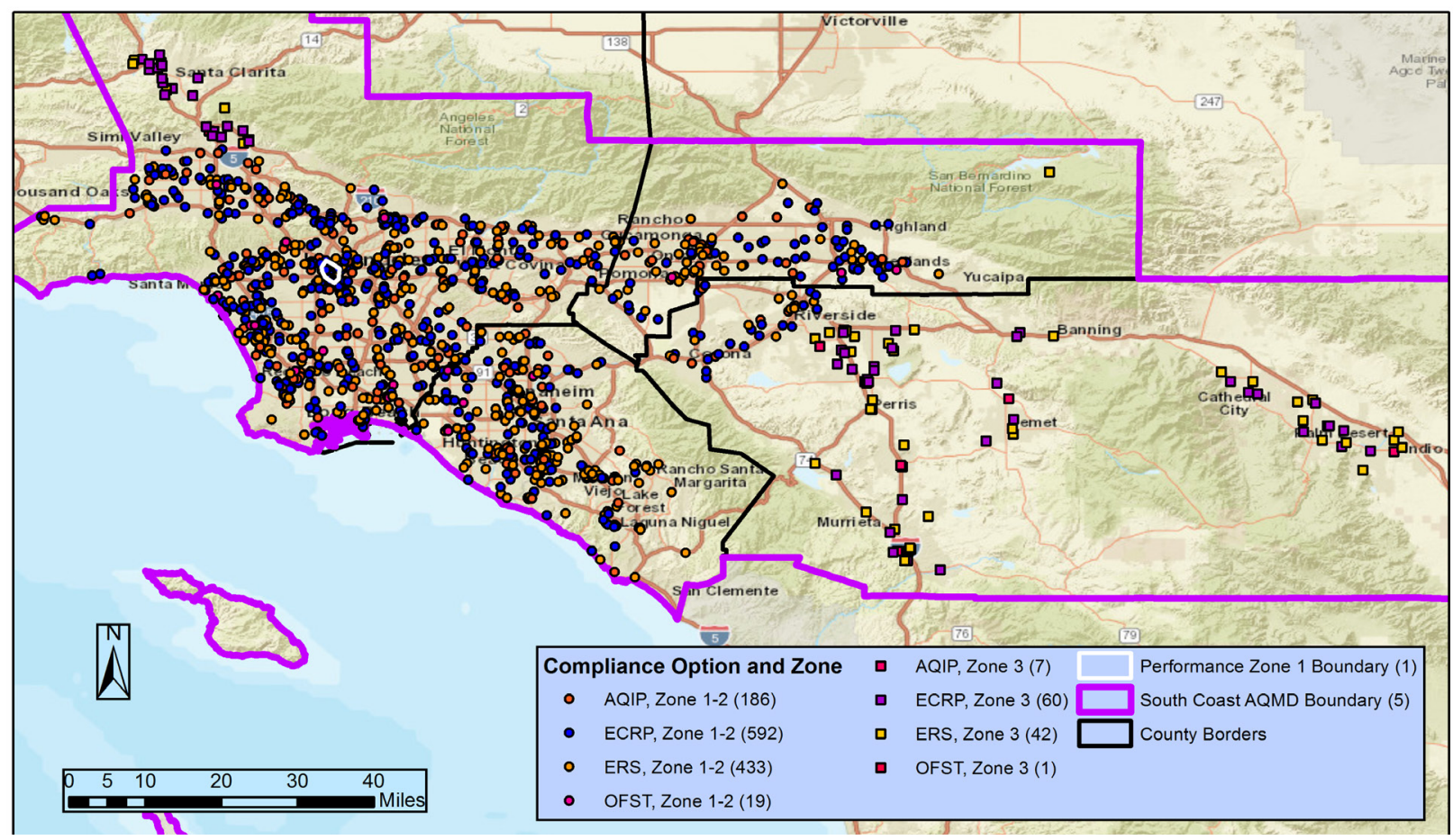

Figure 1. Rule 2202-eligible worksites by compliance option and performance target

Data

The principal data for this project come from a public records request from SCAQMD on the Rule 2202 program over 2004-2016. To investigate the factors that may influence the effectiveness of the EBTR programs, the dependent variables we use are AVR and year-over-year AVR change. The explanatory variables include employer characteristics, land-use characteristics, and mitigation strategies selected by an employer. Table 1 summarizes the description and data source of the dependent and explanatory variables.

We analyzed a total of 2,450 unique, geocoded worksites in the SCAQMD region. In any individual year, between 1,341 and 1,519 worksites in the region with 250 or more employees were included. The full sample includes 18,300 survey results alongside the number of employees and the Standard Industrial Classification (SIC) code, which we aggregate into six categories: (1) Agriculture, Mining, Construction, and Manufacturing, (2) Wholesaling, Transportation, and Utilities, (3) Retail, (4) Finance, Insurance, and Real Estate (FIRE), (5) Services, including hotels, businesses services, repair services, and education, and (6) Public Administration.

Data are also reported for the mitigation strategies which employers undertake. Many, but not all employers who have met their AVR targets also elect to report mitigation strategies theyve undertaken even if the strategies aren't required for compliance with Rule 2202. Since the strategy menu is always changing, complete longitudinal data are not available so employer-level mitigation options are aggregated into three broad groups of strategies: flextime, guaranteed ride home programs, and vanpool 
incentives. Guaranteed ride home programs provide a company vehicle, rental car, taxi, or other means home in the event of overtime, inclement weather, or personal emergency. Vanpool support strategies cover vehicles owned or leased by the employee, employer, or a third party and whether or not the employer provides fuel, maintenance, insurance, or a cash subsidy for users. Flextime was counted as a mitigation strategy since it permits employees to adjust their work hours to accommodate transit schedules or transportation alternatives.

We also analyze the land-use and transit characteristics of the urban environment around employer locations. A cross-sectional (2010) measure of pedestrian node connectivity was gathered from the US EPA's Smart Location Database at the Census block group-level (Ramsay \& Bell, 2014). This was augmented with block group-level 5-year American Community Survey (ACS) samples and decennial Census data from 2000, 2011, and 2016 and appended to the employer-year observation nearest in time measuring population density. A unique value for these variables is generated for each point based on the block group in which it lies plus all other block groups within $1 / 2$-mile, consistent with concepts of egocentric neighborhoods or "egohoods" (Clark et al., 2015; Hipp \& Boessen, 2013).

We use the same egocentric approach to measure the share of land use within 1/8-mile of each worksite to capture its immediate built surroundings. 2008 and 2012 parcel-level land-use data are available from SCAG; the share of nearby land that is residential, single-family residential specifically, commercial, commercial/industrial, or open space is joined to each worksite using the closest available point in time (SCAG, 2016). While analyses such as Dill and Wardell rely on downtown proximity to analyze the urban density gradient, missing from the extant discussion of EBTR has been the local landuse contribution. Finally, we include whether or not a worksite lies within a High-Quality Transit Area (HQTA), defined by SCAG as within 1/2-mile of passenger rail or bus service with 15 -minute or better peak service frequency. Rail station proximity (1/2-mile) is also included. 
Table 1. Variables description and source

\begin{tabular}{|c|c|c|}
\hline & Description & Source \\
\hline \multicolumn{3}{|l|}{ Dependent Variables } \\
\hline $\begin{array}{l}\text { Average vehicle ridership } \\
\text { (AVR) }\end{array}$ & $\begin{array}{l}\text { AVR is calculated as the number of employees arriving at } \\
\text { the worksite between } 6-10 \mathrm{am} \text { divided by the number of } \\
\text { vehicles arriving during the same time. }\end{array}$ & $\begin{array}{l}\text { Southern California’s South Coast } \\
\text { Air Quality Management District } \\
\text { (SCAQMD) }\end{array}$ \\
\hline AVR change & $\begin{array}{l}\text { Year-over-year AVR change between years } t \text { and } t+1 \text { over } \\
\text { 2004-2016. }\end{array}$ & SCAQMD \\
\hline \multicolumn{3}{|l|}{ Explanatory variables } \\
\hline \multicolumn{3}{|l|}{ Employer Characteristics } \\
\hline Employees $(\log )$ & $\begin{array}{l}\text { Natural log of total number of employees of each } \\
\text { employer. }\end{array}$ & SCAQMD; computed by the authors \\
\hline $\begin{array}{l}\text { Employer hit AVR target } \\
(1 / 0)\end{array}$ & $\begin{array}{l}\text { A binary variable indicating whether an employer hit the } \\
\text { AVR target. }\end{array}$ & SCAQMD \\
\hline $\begin{array}{l}\text { Transp, Wholesale, } \\
\text { Comm. }\end{array}$ & $\begin{array}{l}\text { A binary variable indicating whether an employer has } \\
\text { the industry code of Wholesaling, Transportation, and } \\
\text { Utilities. }\end{array}$ & SCAQMD \\
\hline Retail & $\begin{array}{l}\text { A binary variable indicating whether an employer has } \\
\text { the industry code of Retail. }\end{array}$ & SCAQMD \\
\hline $\begin{array}{l}\text { Finance, Insurance, R.E. } \\
\text { (FIRE) }\end{array}$ & $\begin{array}{l}\text { A binary variable indicating whether an employer has } \\
\text { the industry code of Finance, Insurance, and Real Estate. }\end{array}$ & SCAQMD \\
\hline Services & $\begin{array}{l}\text { A binary variable indicating whether an employer has the } \\
\text { industry code of Services, including hotels, businesses } \\
\text { services, repair services, and education. }\end{array}$ & SCAQMD \\
\hline Public Administration & $\begin{array}{l}\text { A binary variable indicating whether an employer has } \\
\text { the industry code of Public Administration. }\end{array}$ & SCAQMD \\
\hline \multicolumn{3}{|l|}{ Land-Use Characteristics } \\
\hline Pop. Density & $\begin{array}{l}\text { Population density (total population divided by acre) in } \\
\text { block groups within } 1 / 2 \text {-mile. }\end{array}$ & $\begin{array}{l}\text { EPA Smart Location database, block } \\
\text { group-level 5-year ACS samples, and } \\
\text { decennial Census data; computed by } \\
\text { the authors }\end{array}$ \\
\hline \% Commercial LU nearby & $\begin{array}{l}\text { Percent of nearby commercial land use within } 1 / 8 \text {-mile } \\
\text { of each worksite }\end{array}$ & $\begin{array}{l}\text { Southern California Association of } \\
\text { Governments' (SCAG); computed by } \\
\text { the authors }\end{array}$ \\
\hline In HQTA (1/0) & $\begin{array}{l}\text { A binary variable indicating whether the worksite is in an } \\
\text { High-Quality Transit Area (HQTA), defined by SCAG } \\
\text { as within } 1 / 2 \text {-mile of passenger rail or bus service with } \\
\text { 15-minute or better peak service frequency. }\end{array}$ & SCAG \\
\hline Pedestrian Connectivity & $\begin{array}{l}\text { Density of pedestrian nodes in block groups within } \\
\text { 1/2-mile. }\end{array}$ & $\begin{array}{l}\text { EPA Smart Location database; com- } \\
\text { puted by the authors }\end{array}$ \\
\hline \multicolumn{3}{|l|}{ Mitigation Strategies } \\
\hline Guar. Ride Home (1/0) & $\begin{array}{l}\text { A binary variable indicating that the employer under- } \\
\text { took a guaranteed ride home program. }\end{array}$ & SCAQMD \\
\hline Flextime $(1 / 0)$ & $\begin{array}{l}\text { A binary variable indicating that the employer under- } \\
\text { took a flextime program. }\end{array}$ & SCAQMD \\
\hline Vanpool support (1/0) & $\begin{array}{l}\text { A binary variable indicating that the employer under- } \\
\text { took a vanpool incentive program. }\end{array}$ & SCAQMD \\
\hline
\end{tabular}




\section{$4 \quad$ Findings-SCAQMD data}

The number of worksites for which the ECRP option was taken — and thus for which survey results are available-was 7,555 over our 13-year sample. However, the share of employers who choose this option decreased from a high of 51.1\% in 2004 and has been consistent at 35\% since 2013 (Figure 2). Only 481 employers completed the AVR survey during 2016. The various ERS options increased in popularity from 2004-2011.

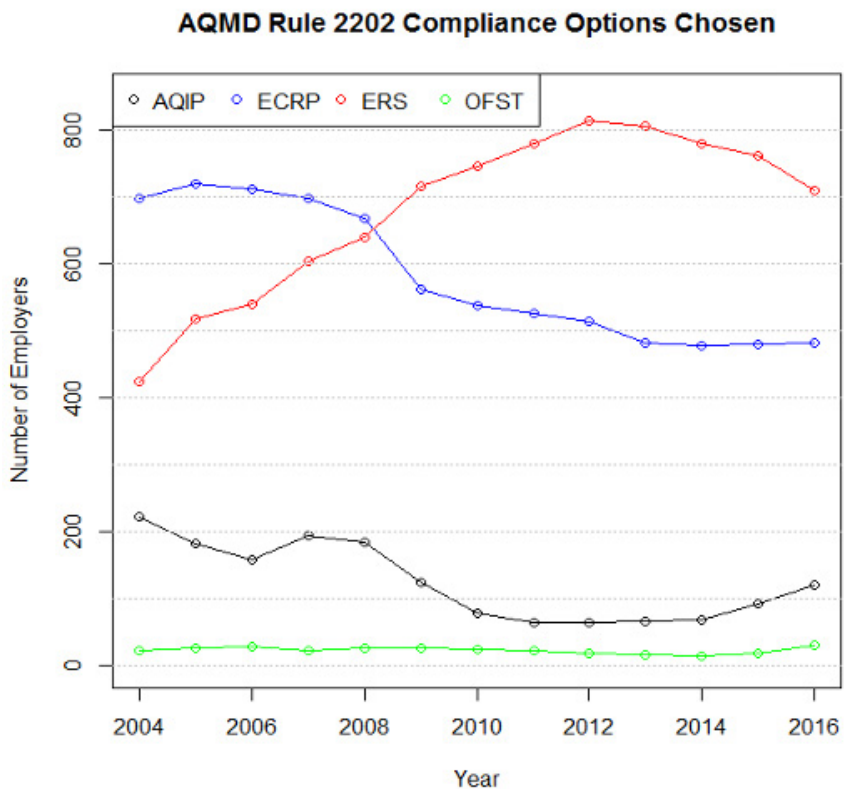

Figure 2. AQMD Rule 2202 compliance options chosen

The data also show that $47.9 \%$ of worksites in Zone 1 (in and around downtown Los Angeles) choose the ECRP survey option, but only $40.7 \%$ of worksites in other zones choose this option (difference significant at $\mathrm{p}<0.0001$ ).

Figure 3 shows aggregate AVR (i.e., not weighted by employer) by target performance zone. Overall AVR values have stayed fairly steady over 2004-2016, ranging from a low of 1.29 in 2004 to a high of 1.35, achieved in 2013. The slight decrease between 2013 and 2016 is consistent with many other reports showing a rebound in driving during the recovery from the Global Financial Crisis (Zolnik, 2016). Average vehicle ridership in Zone 1 is substantially higher and increased from a low of 1.59 in 2004 to a high of 1.82 in 2011 before dropping to 1.75 in 2016. The VMT rebound (or in this case, SOV ridership rebound) is most pronounced in Zone 3, where AVR dropped from 1.28 to 1.18 from 2013-2016.

Mode shares have remained relatively consistent over time, with the SOV share between $66.8 \%$ and $70.2 \%$ across the study period-the highest point representing 2016. Carpool shares declined fairly consistently from their 2004 peak of nearly $21 \%$ to below $15 \%$ in 2016 . The transit mode share decreased noticeably since 2013 when the percentage of respondents selecting bus or rail dropped from $8.1 \%$ to $6.6 \%$. However, the share of respondents walking or bicycling to work increased from roughly $2.5 \%$ to a 2015 high of $4.4 \%$. The highest shares of active transportation are in Zone 2 and not Zone 1 as might be expected, possibly reflecting the fact that Los Angeles' downtown labor pool is typically drawn from afar. 
While the SCAG region encompasses more land area and population than SCAQMD's boundaries, SCAG's 2016 RTP/SCS non-teleworking mode shares provide a basis for comparison: $80.3 \%$ drive alone, $10.8 \%$ carpool, $4.3 \%$ take public transit, and $4.6 \%$ use a form of active transportation (SCAG, 2016). This suggests that employees at large worksites are substantially more likely to carpool and take transit and less likely to drive a single-occupant vehicle.

We also analyze AVR across six broad industrial classifications (Table 2C). While AVR varies slightly across categories, all are between 1.29 and 1.39. Using an analysis of variance (ANOVA), retail worksites have significantly lower AVR than those in FIRE, service, and public administration while public administration worksites have significantly higher AVR than those in construction /manufacturing, wholesale/transportation, and retail.

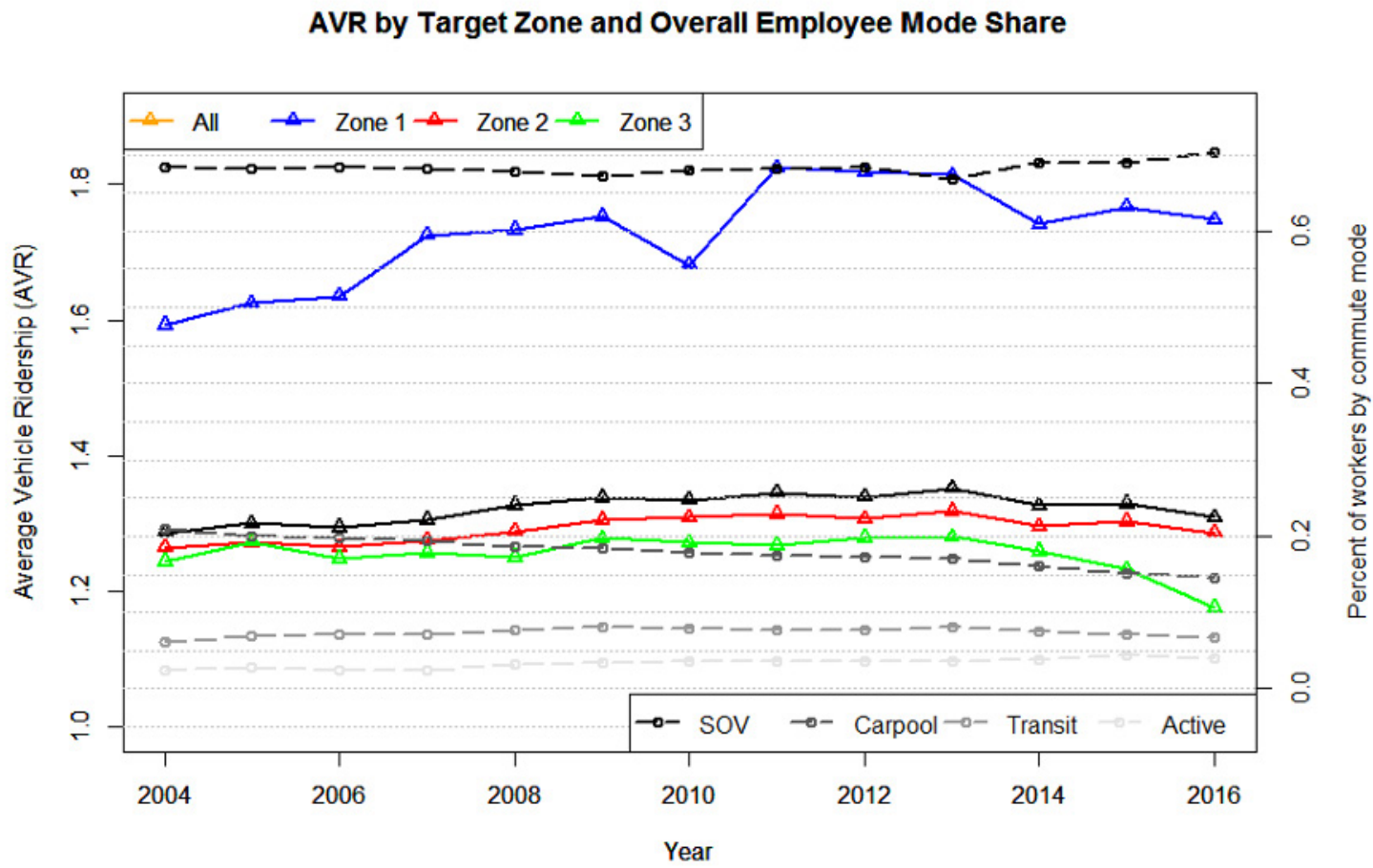

Figure 3. AVR by target zone and overall employee mode share

In terms of mitigation options, Table $2 \mathrm{~A}$ indicates that in most years, over $2 / 3$ of ECRP employers offered some kind of guaranteed ride home program. While flextime data were unavailable after 2013, prior to that, rarely did over $10 \%$ of employers use this strategy. The share of employers offering vanpool increased from $16.5 \%$ in 2004 to $20.7 \%$ in 2010 and remained relatively constant until a substantial increase was seen in 2016 during which an additional 34 employers began offering vanpool benefits. 
Table 2. ECRP Employer Survey Descriptive Statistics

\begin{tabular}{|c|c|c|c|c|c|c|c|c|c|c|c|c|}
\hline \multicolumn{8}{|c|}{ Table 2A. Employer reporting of mitigation strategies: } & \multicolumn{5}{|c|}{ Table 2B. Additional employee survey responses } \\
\hline Year & $\begin{array}{l}\text { Total } \\
\text { employ- } \\
\text { ers } \\
\text { report- } \\
\text { ing }\end{array}$ & $\begin{array}{l}\text { Offers } \\
\text { guaran- } \\
\text { teed } \\
\text { ride } \\
\text { home }\end{array}$ & $\begin{array}{l}\text { Guaran- } \\
\text { teed } \\
\text { ride } \\
\text { home } \\
\%\end{array}$ & $\begin{array}{l}\text { Offers } \\
\text { flex- } \\
\text { time* }^{*}\end{array}$ & $\begin{array}{l}\text { Flex- } \\
\text { time* } \\
\%\end{array}$ & $\begin{array}{l}\text { Offers/ } \\
\text { coordi- } \\
\text { nates } \\
\text { vanpool }\end{array}$ & $\begin{array}{l}\text { Vanpool } \\
\%\end{array}$ & $\begin{array}{l}\text { Total } \\
\text { employee } \\
\text { respon- } \\
\text { dents }\end{array}$ & $\begin{array}{l}\text { Electric } \\
\text { Vehicles }\end{array}$ & $\begin{array}{l}\text { \% Elec- } \\
\text { tric } \\
\text { Vehicles }\end{array}$ & $\begin{array}{l}\text { Parking } \\
\text { Cashout }\end{array}$ & $\begin{array}{l}\text { \% Parking } \\
\text { Cashout }\end{array}$ \\
\hline 2004 & 693 & 461 & $66.5 \%$ & 53 & $7.6 \%$ & 114 & $16.5 \%$ & $1,435,590$ & 891 & $0.06 \%$ & 0 & $0.00 \%$ \\
\hline 2005 & 718 & 574 & $79.9 \%$ & 59 & $8.2 \%$ & 157 & $21.9 \%$ & $1,477,524$ & 1184 & $0.08 \%$ & 0 & $0.00 \%$ \\
\hline 2006 & 709 & 480 & $67.7 \%$ & 46 & $6.5 \%$ & 115 & $16.2 \%$ & $1,509,283$ & 1803 & $0.12 \%$ & 0 & $0.00 \%$ \\
\hline 2007 & 695 & 465 & $66.9 \%$ & 54 & $7.8 \%$ & 113 & $16.3 \%$ & $1,479,425$ & 1689 & $0.11 \%$ & 0 & $0.00 \%$ \\
\hline 2008 & 666 & 434 & $65.2 \%$ & 54 & $8.1 \%$ & 107 & $16.1 \%$ & $1,516,264$ & 1182 & $0.08 \%$ & 0 & $0.00 \%$ \\
\hline 2009 & 560 & 409 & $73.0 \%$ & 70 & $12.5 \%$ & 110 & $19.6 \%$ & $1,344,423$ & 617 & $0.05 \%$ & 0 & $0.00 \%$ \\
\hline 2010 & 537 & 373 & $69.5 \%$ & 50 & $9.3 \%$ & 111 & $20.7 \%$ & $1,265,880$ & 742 & $0.06 \%$ & 0 & $0.00 \%$ \\
\hline 2011 & 523 & 358 & $68.5 \%$ & 50 & $9.6 \%$ & 113 & $21.6 \%$ & $1,315,505$ & 946 & $0.07 \%$ & 0 & $0.00 \%$ \\
\hline 2012 & 514 & 326 & $63.4 \%$ & 5 & $1.0 \%$ & 105 & $20.4 \%$ & $1,253,073$ & 1428 & $0.11 \%$ & 502 & $0.04 \%$ \\
\hline 2013 & 482 & 312 & $64.7 \%$ & 0 & $0.0 \%$ & 100 & $20.7 \%$ & $1,216,176$ & 2331 & $0.19 \%$ & 427 & $0.04 \%$ \\
\hline 2014 & 477 & 303 & $63.5 \%$ & 0 & $0.0 \%$ & 98 & $20.5 \%$ & $1,210,941$ & 3927 & $0.32 \%$ & 333 & $0.03 \%$ \\
\hline 2015 & 476 & 286 & $60.1 \%$ & 0 & $0.0 \%$ & 92 & $19.3 \%$ & $1,286,458$ & 6546 & $0.51 \%$ & 419 & $0.03 \%$ \\
\hline 2016 & 481 & 349 & $72.6 \%$ & 0 & $0.0 \%$ & 126 & $26.2 \%$ & $1,333,079$ & 12376 & $0.93 \%$ & 467 & $0.04 \%$ \\
\hline \multicolumn{13}{|c|}{ Table 2C. AVR by Employer's Industrial Classification } \\
\hline \multicolumn{8}{|c|}{ Groupings of SIC (Industry) Codes - Description } & Avg. AVR & \multicolumn{4}{|c|}{ ANOVA, significant differences $(\mathrm{p}<0.05)$} \\
\hline \multicolumn{7}{|c|}{1 Agricultre, Forestry, Fishing, Mining, Construction, Manufacturing } & & 1.335 & \multicolumn{4}{|c|}{ vs. \#5 and vs. \#6 } \\
\hline \multicolumn{7}{|c|}{2 Wholesale trade, transportation, communication, utilities } & & 1.328 & \multicolumn{4}{|l|}{ vs. \#6 } \\
\hline \multicolumn{7}{|c|}{3 Retail trade } & & 1.290 & \multicolumn{4}{|c|}{ vs. \#4, \#5, and \#6 } \\
\hline \multicolumn{7}{|c|}{4 Finance, insurance, and real estate } & & 1.361 & \multicolumn{4}{|l|}{ vs. \#3 } \\
\hline \multicolumn{7}{|c|}{5 Services, including hotels, business services, repair, and educational } & & 1.374 & \multicolumn{4}{|c|}{ vs. \#1 and \#3 } \\
\hline \multicolumn{7}{|c|}{6 Public administration } & & 1.396 & \multicolumn{4}{|c|}{ vs. \#1, \#2, and \#3 } \\
\hline
\end{tabular}

The commute survey also asks how many individual respondents take an electric vehicle-a share which has increased dramatically but which by 2016 remains just below 1\%. Parking cash out programs, which refund subsidized parking to employees who choose alternative transportation, have been recorded since 2012 though participation is extremely low (see Table 2B).

\section{$5 \quad$ Findings-Correlation analysis}

Figure 4 displays the correlation between AVR and land-use/travel characteristics evaluated at the employer level. Lines indicate how the correlation changed over time, with the total (2004-2016) correlation coefficient displayed in the legend. 
Correlation between AVR and nearby built environment characteristics

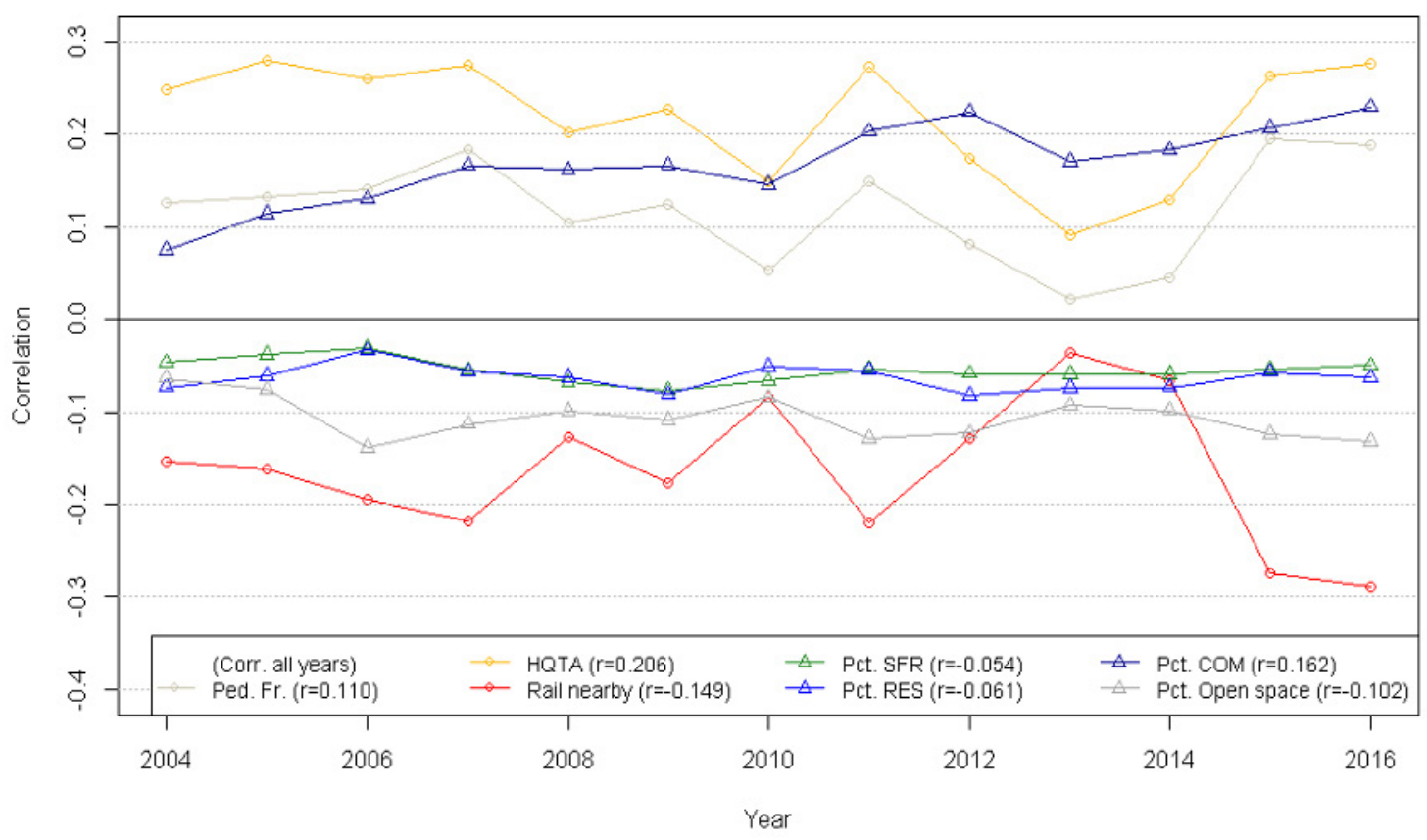

Figure 4. Correlation between AVR and nearby built enviornment characteristics

Simple Pearson's correlation coefficients provide an initial look the relationship between AVR and land-use and locational characteristics. Whether an employer has single-family residential or overall residential land nearby is immaterial to its AVR — correlations are slightly negative but insignificant, suggesting that a strategy which promotes land-use mixing is not associated directly with AVR here. However, worksites with more nearby commercial land use have higher AVR ( $\mathrm{r}=0.162)$. Jobsites with more open space nearby have lower AVR ( $\mathrm{r}=-0.102)$, which is likely indicative of farther-flung worksites far from other urbanized land use-which tend to be less amenable to alternative transportation. The pedestrian friendliness of the surrounding area is weakly positively correlated with AVR ( $r=0.110)$; whether high-quality transit is present is strongly positively correlated with AVR $(r=0.206)$. Unexpectedly, being near a rail station tends to be associated with lower AVR ( $r=-0.149)$.

\section{Findings-Multivariate analysis}

The purpose of this analysis is to determine which land-use characteristics, employer characteristics, and compliance strategies explain differences in AVR and AVR change across large worksites in Southern California. While panel data allow for rich longitudinal analysis, three challenges arise. First, survey results are only available for employers who participated in ECRP. Therefore, the universe of this analysis is the (decreasing) share of large employers who have signaled a commitment to sustainable commuting in this manner. Second, ECRP employers who meet their AVR target are not required to engage in or report mitigation strategies. While many still do, these variables are only robust for employers who are below the target necessitating a binary variable to this effect to aid in robustness. Third, while the dependent variable exists in all years, certain explanatory variables (e.g. land use, HQTAs, and pedestrian 
friendliness) only exist in certain years which would result in an unbalanced panel. To minimize the risk of model misspecification with panel methods, we use a simpler pooled cross-sectional model which combines all 13 years' worth of employer-year observations into a single sample (Dielman, 1983). Two model forms are specified:

$$
A V R_{t}=\alpha+\beta_{1} L O C_{t}+\beta_{2} E M P_{t}+\beta_{3} M I T_{t}+\beta_{4} Y R_{t}+\varepsilon_{t}
$$

where $A V R_{t}$ is the average vehicle ridership in year $t, L C_{t}$ is a matrix of locational characteristics in year $t$ (or the closest available year) which includes a binary variable indicating whether the worksite is in an HQTA, the level of pedestrian connectedness, the population density (pop/acre), and the percent of nearby commercial land use. $\mathrm{EMP}_{\mathrm{t}}$, represents employer characteristics, includes the (log-transformed) number of workers, a control variable indicating whether the employer met its AVR target, and five dummy variables covering six industry categories. $\mathrm{MIT}_{t}$ is a matrix of binary variables representing the ECRP mitigation options chosen in each year: guaranteed ride home, vanpool, or flextime as well as a control variable for whether or not these strategies were actually used for compliance versus voluntarily reported (not shown). $\mathrm{YR}_{\mathrm{t}}$ is a matrix of dummy variables of each year (2004-2016) and allows other covariates to be interpreted independently of time. The reference category is 2004 and $\mathrm{YR}_{t}$ estimates are not reported since they do not have a substantive interpretation.

$$
\Delta A V R_{t, t+1}=\alpha+\beta_{1} L O C_{t}+\beta_{2} E M P_{t}+\beta_{3} M I T_{t}+\beta_{4} Y R_{t}+\varepsilon_{t, t+1}
$$

In contrast to the pooled cross-sectional model in Equation 1, Equation 2 evaluates a pooled sample of year-over-year AVR change between years $t$ and $t+1$. For example, the change in AVR between 20042005 would be explained using 2004 locational and employer characteristics and mitigation strategies. The sample size decreases in Equation 2 from 6,647 to 5,402 since there is no AVR change evaluated in the first year of the sample and it is restricted to employers present in both $t$ and $t+1$. While AVR and AVR change are strongly correlated $(r=0.455)$, conceptually they are very different outcome measures. Empirical analyses of regional economic growth provide some context: growth in GDP can be positively or negatively impacted by the level of GDP (Barro \& Sala-i-Martin, 1992). Similarly, if capacity for further AVR gains is exhausted, we might expect a different sign in AVR versus AVR change models.

Both models are solved using ordinary least squares (OLS) regression with cluster robust standard errors - this is done to guard against the fact that employers are observed multiple times in the data and we take care to rely principally on statistical test results rather than coefficient estimate magnitudes to draw major conclusions. Since SCAQMD's zone-based AVR targets are generally reflective of regional density and land-use differences, we chose to run four regressions for either equation: one for all employers and one for each SCAQMD compliance zone. Zone 1 is a homogenous area with high job concentration, features the area's best regional transit connectivity, and until recently had very little residential land. Zone 3 is made up of the farthest reaches of the SCAQMD region including Santa Clarita and the Coachella Valley. Since the vast majority of large employers are in the large and varied Zone 2, the all zone results are expected to be closest to Zone 2 results but we anticipate coefficient estimates in Zones 1 and 3 may differ notably. 


\subsection{Equation 1: Explaining AVR}

Results for all eight specifications are found in Table 3. Goodness of fit ranges from $\mathrm{R}^{2}=0.197$ for the small Zone 3 model to 0.517 for the Zone 2 model. Employer size has an inverse relationship to AVRvehicle ridership is higher for smaller employees in Zone 1 and overall. While the sample includes only employers of 250 and above, this indicates that smaller relative employer size is associated with better AVR, thus an expansion of EBTR to even smaller employees may be beneficial. This relationship is no longer significant in Zones 2 and 3, indicating the importance of downtown LA in this result.

In the Zone 2 model, variables for three industry types are related to significantly lower AVR compared to the reference category, which includes agriculture, construction, and manufacturing. FIRE is most negatively associated with AVR, followed closely by retail, then public administration. In the all employers model, only retail is significantly associated with lower AVR. Industrial category is found no difference in Zones 1 or 3 . The density of the residential population within $1 / 2-$ mile of a worksite has minimal discernable effect on AVR. This result is anticipated since commercial sites suitable for large employers may not be near residential land. The percent of commercial land use within $1 / 8$-mile may be a better indicator of the character of the nearby built environment. The effect of this is positive and significant across all employers, although it is not significant in the zone-specific models indicating that commercial land-use share varies strongly by zone (the mean value is $80.7 \%, 53.9 \%$, and $29.1 \%$ in Zones 1, 2, and 3 respectively).

Being in a high-quality transit area is the most consistently strong predictor $(\mathrm{p}<0.01)$ of AVR across all samples except Zone 3 in which only one worksite is in an HQTA. While this result doesn't indicate causality, i.e., that HQTA location causes higher AVR, this strong association provides evidence that employers choosing to locate in HQTAs might expect higher AVR. Pedestrian connectivity is a strong predictor of AVR in Zone 2 but is not significant elsewhere. While we might expect this relationship to be strongest in Zone 1, most of that zone already has high levels of pedestrian connectivity and low variance (mean=12.6, std.dev. $=2.5$ ). In contrast, it is in Zone 2 where the more highly variable level of pedestrian connectivity (mean=11.3, std.dev. $=4.7$ ) is a strong predictor of an employer's AVR.

As expected, the control variable for whether the AVR target was met is positive and significant and allows for improved inference on mitigation strategy variables. Participation in guaranteed ride home programs shows a negative, yet insignificant relationship with AVR while flextime is positively though insignificantly associated with AVR. Of the strategies able to be analyzed, only vanpool shows a significant relationship with AVR—weakly positive, and only in Zone 2 . 
Table 3. Model results

\begin{tabular}{|c|c|c|c|c|c|c|c|c|}
\hline & \multicolumn{4}{|c|}{ OLS models of AVR } & \multicolumn{4}{|c|}{ OLS models of year-over-year AVR change } \\
\hline & $\begin{array}{l}\text { All } \\
\text { Employers }\end{array}$ & $\begin{array}{l}\text { Employers } \\
\text { in Zone } 1\end{array}$ & $\begin{array}{l}\text { Employers } \\
\text { in Zone } 2\end{array}$ & $\begin{array}{l}\text { Employers } \\
\text { in Zone } 3\end{array}$ & $\begin{array}{l}\text { All } \\
\text { Employers }\end{array}$ & $\begin{array}{l}\text { Employers } \\
\text { in Zone } 1\end{array}$ & $\begin{array}{l}\text { Employers } \\
\text { in Zone } 2\end{array}$ & $\begin{array}{l}\text { Employers } \\
\text { in Zone } 3\end{array}$ \\
\hline \multirow[t]{2}{*}{ Constant } & $1.320^{* * *}$ & $1.492^{* * *}$ & $1.262^{* * *}$ & $2.035^{* *}$ & -0.00474 & $0.199^{* * *}$ & -0.011 & 0.0668 \\
\hline & $(-0.0636)$ & $(-0.192)$ & $(-0.0319)$ & $(-0.795)$ & $(-0.0111)$ & $(-0.0714)$ & $(-0.007)$ & $(-0.144)$ \\
\hline \multicolumn{9}{|l|}{ Employer Characteristics } \\
\hline \multirow[t]{2}{*}{ Employees $(\log )$} & $-0.0213^{* *}$ & $-0.0869^{* *}$ & -0.0053 & -0.132 & -0.0023 & $-0.0225^{* *}$ & -0.0003 & -0.0157 \\
\hline & $(-0.0085)$ & $(-0.0359)$ & $(-0.0047)$ & $(-0.129)$ & $(-0.0014)$ & $(-0.0097)$ & $(-0.0009)$ & $(-0.018)$ \\
\hline \multirow[t]{2}{*}{ Employer hit AVR target $(1 / 0)$} & $0.482^{* * *}$ & $0.661^{* * *}$ & $0.395^{* * *}$ & $0.325^{* * *}$ & $0.0382^{* * *}$ & $0.0640^{* * *}$ & $0.0336^{* * *}$ & $0.0468^{* * *}$ \\
\hline & $(-0.0281)$ & $(-0.0547)$ & $(-0.0166)$ & $(-0.103)$ & $(-0.0042)$ & $(-0.0137)$ & $(-0.0036)$ & $(-0.0166)$ \\
\hline \multirow[t]{2}{*}{ Transp, Wholesale, Comm.^ } & -0.0048 & 0.115 & -0.0126 & 0.0009 & 0.0070 & -0.00524 & 0.0062 & 0.0223 \\
\hline & $(-0.0208)$ & $(-0.135)$ & $(-0.019)$ & $(-0.0917)$ & $(-0.0046)$ & $(-0.0342)$ & $(-0.0051)$ & $(-0.0163)$ \\
\hline \multirow[t]{2}{*}{ Retail` $^{\wedge}$} & $-0.0830^{* * *}$ & 0.173 & $-0.0409^{* * *}$ & -0.0595 & 0.0064 & 0.018 & $0.0129^{* * *}$ & -0.0089 \\
\hline & $(-0.0187)$ & $(-0.162)$ & $(-0.0145)$ & $(-0.102)$ & $(-0.0048)$ & $(-0.0766)$ & $(-0.0042)$ & $(-0.0213)$ \\
\hline \multirow[t]{2}{*}{ Finance, Insurance, R.E.^ } & -0.0022 & 0.125 & $-0.0665^{* * *}$ & - & $0.0136^{* * *}$ & -0.0139 & $0.0133^{* * *}$ & - \\
\hline & $(-0.0254)$ & $(-0.133)$ & $(-0.0148)$ & - & $(-0.0039)$ & $(-0.0477)$ & $(-0.0039)$ & - \\
\hline \multirow[t]{2}{*}{ Services $^{\wedge}$} & -0.0014 & 0.205 & -0.018 & 0.156 & $0.0098^{* * *}$ & -0.0135 & $0.0083^{* * *}$ & 0.0254 \\
\hline & $(-0.0177)$ & $(-0.143)$ & $(-0.0115)$ & $(-0.139)$ & $(-0.0033)$ & $(-0.0548)$ & $(-0.0025)$ & $(-0.0207)$ \\
\hline \multirow[t]{2}{*}{ Public Administration^^} & -0.0094 & 0.176 & $-0.0236^{*}$ & -0.0753 & $.00517^{*}$ & -0.0308 & $0.0068^{* * *}$ & -0.0177 \\
\hline & $(-0.0159)$ & $(-0.147)$ & $(-0.0129)$ & $(-0.103)$ & $(-0.0028)$ & $(-0.0419)$ & $(-0.0026)$ & $(-0.023)$ \\
\hline \multicolumn{9}{|l|}{ Land-Use Characteristics } \\
\hline \multirow[t]{2}{*}{ Pop. Density (Pop/acre) } & $1.82 \mathrm{E}-09$ & $-3.38 \mathrm{E}-08$ & $-2.00 \mathrm{E}-09$ & $1.80 \mathrm{E}-08$ & $1.01 \mathrm{E}-09$ & $-1.77 \mathrm{e}-08^{*}$ & 4.64E-11 & $6.23 \mathrm{E}-09$ \\
\hline & $(0)$ & $(0)$ & $(0)$ & $(0)$ & $(0)$ & $(0)$ & $(0)$ & $(0)$ \\
\hline \multirow[t]{2}{*}{$\%$ Commercial LU nearby } & $0.109^{* * *}$ & -0.0552 & 0.0129 & 0.449 & $0.0080^{* *}$ & -0.0362 & 0.0033 & 0.0718 \\
\hline & $(-0.0278)$ & $(-0.128)$ & $(-0.0111)$ & $(-0.404)$ & $(-0.004)$ & $(-0.0406)$ & $(-0.0028)$ & $(-0.0507)$ \\
\hline \multirow[t]{2}{*}{ In HQTA (1/0) } & $0.0693^{* * *}$ & $0.383^{* * *}$ & $0.0275^{* * *}$ & -0.286 & -0.0003 & 0.0093 & -0.0013 & - \\
\hline & $(-0.0129)$ & $(-0.0919)$ & $(-0.0077)$ & $(-0.215)$ & $(-0.0019)$ & $(-0.0453)$ & $(-0.0016)$ & - \\
\hline \multirow[t]{2}{*}{ Pedestrian Connectivity } & -0.0004 & 0.0005 & $0.0021^{* * *}$ & -0.0272 & -0.0004 & 0.0008 & -0.0003 & -0.0026 \\
\hline & $(-0.0024)$ & $(-0.0076)$ & $(-0.0008)$ & $(-0.0234)$ & $(-0.0003)$ & $(-0.0024)$ & $(-0.0002)$ & $(-0.0034)$ \\
\hline \multicolumn{9}{|l|}{ Mitigation Strategies } \\
\hline \multirow[t]{2}{*}{ Guar. Ride Home (1/0) } & -0.0212 & -0.0304 & -0.0112 & -0.106 & 0.0030 & -0.0327 & $0.0065^{* * *}$ & 0.0146 \\
\hline & $(-0.015)$ & $(-0.0538)$ & $(-0.0081)$ & $(-0.0744)$ & $(-0.0032)$ & $(-0.0235)$ & $(-0.0024)$ & $(-0.0153)$ \\
\hline \multirow[t]{2}{*}{ Flextime $(1 / 0)$} & 0.0226 & 0.0831 & 0.00499 & -0.0454 & 0.0012 & 0.00261 & 0.0015 & -0.0211 \\
\hline & $(-0.0159)$ & $(-0.079)$ & $(-0.0097)$ & $(-0.0624)$ & $(-0.0034)$ & $(-0.0172)$ & $(-0.0034)$ & $(-0.0171)$ \\
\hline \multirow[t]{2}{*}{ Vanpool support $(1 / 0)$} & -0.0037 & 0.0031 & $0.0131^{*}$ & -0.0862 & -0.0004 & -0.0005 & -0.0005 & -0.0337 \\
\hline & $(-0.009)$ & $(-0.0444)$ & $(-0.0075)$ & $(-0.0916)$ & $(-0.002)$ & $(-0.0256)$ & $(-0.0018)$ & $(-0.0208)$ \\
\hline $\mathrm{N}$ & 7505 & 653 & 6376 & 476 & 6221 & 508 & 5319 & 394 \\
\hline R-sq & 0.400 & 0.499 & 0.517 & 0.197 & 0.037 & 0.063 & 0.038 & 0.086 \\
\hline
\end{tabular}

Standard errors in parentheses. ${ }^{*} \mathrm{p}<0.10,{ }^{* *} \mathrm{p}<0.05,{ }^{* * *} \mathrm{p}<0.01$

$\wedge$ Categorical variable for industrial category. Reference category is Agriculture/mining/construction/manufacturing 


\subsection{Equation 2: Explaining AVR change}

The structure of Model 2 allows us to investigate the effect of a policy on any changes found by the next year's employee commute survey —an outcome measure which has frustrated prior research efforts. As this model investigates change, variances on the dependent variable and model fit are expected to be lower ( $\mathrm{R}^{2}$ values of $0.037-0.086$ as shown in Table 2 ), though a number of variables are significant predictors of AVR increase.

In Zone 1, downtown Los Angeles, we find that smaller employers are significantly more likely to experience bigger increases in AVR. While FIRE employers were associated with lower AVR, they are most strongly and consistently associated with AVR gains. Being a retail employer is associated with improved AVR only in Zone 2 and follows closely behind FIRE in magnitude. Service employment also shows significant reduction potential relative to the reference category—about $60-70 \%$ the magnitude of FIRE. Public administration, transportation/wholesale/communications, and agriculture/manufacturing/construction round out the list of industry categories by AVR reduction potential.

Residential population density is negative but is only significant (weakly) in Zone 1, an area which has only recently seen substantial residential construction near the core employment center. This would indicate that the less residentially dense areas near downtown LA experience greater AVR gain. Further investigation of specific sites may be required to fully understand why this is the case. The share of commercial land use nearby is a positive and significant driver of AVR gain only in the all employers model providing evidence that AVR improvement is more likely to occur in areas that resemble commercial districts rather than those mixed with other land uses - especially when downtown LA is included in regional totals. While high quality transit was a very strong predictor of AVR, it has no significant relationship with AVR increase. Pedestrian connectivity is also statistically unrelated to AVR change. That these two variables are strongly related to high AVR; however, on the margin, further AVR improvement may be challenging in areas which may have maxed-out potential AVR gains.

Encouragingly, undertaking a guaranteed ride home strategy is significantly associated with AVR increases in the large Zone 2 sample. While vanpool strategies show a relationship with AVR itself, that guaranteed ride home programs associated with AVR improvement shows promise for untapped potential — especially in the varied, low and medium-density landscapes of much of Zone 2. However, vanpool and flextime strategies show no significant relationship to AVR change in these models, though this could be impacted by flextime data limitations.

\section{$7 \quad$ Discussion and conclusions}

The objectives of this study were to understand the participation rates, characteristics, and spatial distribution of participants in Southern California's EBTR program and to analyze which land-use and location characteristics, employer characteristics, and mitigation strategies were related to average vehicle ridership and change in average vehicle ridership over 2004-2016. This is the first study of which we are aware which analyzes these three drivers of work travel behavior over a long time horizon using program data. While EBTR programs were originally intended to reduce commute-based air pollution, since SB375's passage in 2008 travel demand management (TDM) now has an additional motivator: regional GHG emissions reduction targets. That legislation's linkage between land use and transportation planning also suggests that EBTR programs and TDM should consider the land-use context more strongly. Employer participation in SCAQMD's ECRP option has decreased since 2004, suggesting that the cost of fee payments and the availability of emissions credits for purchase may have become financially or administratively more attractive than engagement with employees' commutes. While emissions credits 
and re-invested fee payments to SCAQMD fund other forms of pollution mitigation, only ECRP can be considered a TDM strategy capable of stimulating behavior change- - something which appears decreasingly attractive.

Results for employee mode share are somewhat consistent with concerns over the recent "VMT rebound;" they also indicate that larger employers who choose the ECRP option have lower drive-alone shares. Despite a long-term decline in carpool share, car/vanpools at large employers show some promise. They tend to be easier to coordinate at large worksites. As the results show, carpool rates are higher at ECRP employers than overall, the number of ECRP employers offering vanpool benefits in 2016 increased substantially, and across much of the study area vanpool support is related to higher AVR. However, if increasing AVR is a program's explicit goal, offering guaranteed ride home programs shows the most promise. Rather than coordinating daily car/vanpools or altering work hours, guaranteed ride home programs may be less "invasive" since they are used infrequently, and can provide peace of mind to risk-averse workers such that they switch to non-SOV commuting. Given the rise of transportation network companies such as Uber and Lyft, providing guaranteed rides home may become cheaper and easier.

These findings are somewhat consistent with Herzog's multi-region finding that nonfinancial incentives for VMT reduction could be effective as well as Dill and Wardell's finding that flextime and guaranteed ride home programs are effective in Portland. However, the latter study is unable to comment on AVR change, and differences in program administrative details and urban geography severely hamper interregional comparison.

Models also suggest that smaller employers are more likely to achieve AVR gains and even those below 250 employees deserve consideration. This is consistent with the objectives of the recently passed AB2548 which mandates tax-free transit, carpool, and vanpool deductions be made available to Los Angeles County employers of between 50-249 workers. While this law will not enable a bona-fide EBTR program and covers a smaller spatial extent than Rule 2202, this paper's results suggest that well-placed and well-advertised incentives may be effective in promoting sustainable commuting.

Finally, results indicate the land-use and transportation context near an employer matters. Good pedestrian connectivity in suburban areas is important, as is high quality transit. While HQTAs were associated with AVR and not AVR change, the strength of the result for AVR suggests that if future landuse strategies can promote employer location in those areas, AVR improvement will likely follow. Additionally, AVR improvement is more likely in areas that resemble commercial districts than in mixed-use neighborhoods. Since the study only investigates large employers, we cannot exclude the possibility that smaller workplaces providing residential services may demonstrate high AVR in mixed-use neighborhoods. But our results do suggest that promoting job centers or worksite concentration in places with good connectivity could show more promise than land-use mixing.

FIRE and retail sectors are associated with lower AVR, but also with AVR increase. Both categories might be considered residential-serving industries, in particular since the region's FIRE employment is known to be heavy on real estate finance. While FIRE and retail may be promising areas of future AVR gains, this sample is restricted to worksites over 250 employees, which is not consistent with the smaller, dispersed stores and offices which typically characterize residential-serving businesses.

This study has shortcomings principally due to the nature of Rule 2202 and the limited sample for the employee survey, which may suffer from some selection bias. Our understanding of mitigation options is limited by aggregated program data and further investigation into why specific options are chosen is needed. However, the sample investigated is large, comprehensive, and longitudinal and allows us to measure performance improvement over time. While programs which provide incentives for commute behavior change without an option for fee-in-lieu payments are stronger forms of TDM, the 
declining popularity of survey and mitigation options suggests that future study should consider employers' financial incentives more closely, with a focus on employers who voluntarily promote sustainable commuting through ECRP or their own programs. Location and built environment characteristics also need to be taken into account, as well as job clustering and the spatial extent of the employer's labor pool which contribute to the viability of non-SOV commuting and mitigation strategies. Nudging workers and their employers toward sustainable transportation choices is a multi-faceted, long-term effort, but EBTR in its current and improved future form deserves a major role in the planner's TDM toolkit and shows promise for helping regions meet GHG reduction targets in addition to congestion and air pollution reduction. 


\section{References}

Barro, R. J., \& Sala-i-Martin, X. (1992). Convergence. Journal of Political Economy, 100(2), 223-251.

Clark, W. A. V., Anderson, E., Östh, J., \& Malmberg, B. (2015). A Multiscalar analysis of neighborhood composition in Los Angeles, 2000-2010: A location-based approach to segregation and diversity. Annals of the Association of American Geographers, 105(6), 1260-1284. doi:10.1080/00045608 .2015 .1072790

Dielman, T. E. (1983). Pooled cross-sectional and time series data: A survey of current statistical methodology. The American Statistician, 37(2), 111-122.

Dill, J. (1998). Mandatory employer-based trip reduction: What happened? Transportation Research Record: Journal of the Transportation Research Board, 1618, 103-110. doi:10.3141/1618-12

Dill, J., \& Wardell, E. (2018). Factors affecting worksite mode choice. Transportation Research Record: Journal of the Transportation Research Board, 1994(1), 51-57. doi:10.3141/1994-07

Ewing, R., \& Cervero, R. (2010). Travel and the built environment. Journal of the American Planning Association, 76(3), 265-294. doi:10.1080/01944361003766766

Herzog, E., Bricka, S., Audette, L., \& Rockwell, J. (2006). Do employee commuter benefits reduce vehicle emissions and fuel consumption? Results of fall 2004 survey of best workplaces for commuters. Transportation Research Record: Journal of the Transportation Research Board, 1956, 34-41. doi:10.3141/1956-05

Hipp, J. R., \& Boessen, A. (2013). Egohoodsas waves washing across the city: A new measure of "neighborhoods." Criminology, 51(2), 287-327. doi:10.1111/1745-9125.12006

Kneisel, R. (2001). Voluntary ridesharing after deregulation: Findings from work sites exempted from California Rule 2202 on-road motor vehicle mitigation options. Transportation Research Record: Journal of the Transportation Research Board, 1765, 20-26. doi: 10.3141/1765-04

Ramsay, K., \& Bell, A. (2014). Smart location database. Retrieved from https:/www.epa.gov/sites/ production/files/2014-03/documents/sld_userguide.pdf

Salon, D., Boarnet, M. G., Handy, S., Spears, S., \& Tal, G. (2012). How do local actions affect VMT? A critical review of the empirical evidence. Transportation Research Part D: Transport and Environment, 17(7), 495-508. doi:10.1016/j.trd.2012.05.006

SCAG. (2016). The 2016-2040 regional transportation plan/sustainable communities strategy. Los Angeles: Southern California Association of Governments.

Skelton, G. (2008). A smart plan for smart growth, Los Angeles Times. Retrieved from http://articles. latimes.com/2008/aug/21/local/me-cap21

United States Department of Transportation (2019). Transportation Demand Management. Last modified November 1, 2019. Retrieved from https:/ops.fhwa.dot.gov/plan4ops/trans_demand.htm

Zolnik, E. J. (2016). Inducing demand by expanding road capacity: Controlling for the rebound effect. Annals of the American Association of Geographers, 106(4), 837-852. doi:10.1080/24694452.20 16.1167584

Zuehlke, K., \& Guensler, R. (2007). Employer perceptions and implementation of commute alternatives strategies. Journal of Public Transportation, 10(4), 171-194. 